\title{
NEM LITERACIA, NEM LETRAMENTO, MAS LEITURESCRITA E LESCREVER
}

\author{
NEITHER LITERACY NOR LITERACY, BUT READING AND WRITING
}

\author{
Dagoberto Buim Arena \\ Universidade Estadual Paulista Júlio de Mesquita Filho - Câmpus de Marília \\ dagobertobuim@gmail.com
}

\section{RESUMO}

O artigo ensaia alternativas teóricas em relação a documentos oficiais de anos recentes, como o Decreto $N^{0}$ 9.765, de 11 de abril de 2019, a Base Nacional Comum Curricular e as formulações do Pacto Nacional pela Alfabetização na Idade Certa, que substituíram o conceito de alfabetização pelos de letramento, de alfabetizar-letrando e de literacia, com a intenção de apontar que o núcleo da concepção de alfabetização permanece nos três documentos (o de consciência fonológica), embora tenham sido paridos por forças políticas divergentes; as divergências não seriam nucleares, mas periféricas; o conceito de letramento e de literacia adaptados à pedagogia brasileira, a redução e restrição do conceito de alfabetização e a proposta de revitalização de outro, o de lecto-escrita, e criação de outros: leiturescrita e lescrever, em palavras aglutinadas; o questionamento da hegemonia do conceito da linguagem escrita alfabética; a linguagem escrita no meio digital, os métodos alfabéticos e a consciência fonológica; a linguagem escrita no meio digital derivada da tipografia e o conceito de caractere; a escrita digital, construída com caracteres, seus gestos e suportes e, finalmente, as crianças poliatentas e a sua recusa a modos de pensar e de usar instrumentos, suportes e gestos congelados em outro tempo histórico. Assim, o artigo rompe o consenso ao contestar a natureza predominantemente alfabética da escrita e assumir o de consciência gráfica em um mundo digitalizado e sugere, na esteira de estudiosos franceses, lescrever e leiturescrita, conceitos que fundem os atos com a escrita em uma única palavra.

Palavras-chave: Consciência gráfica; Leiturescrita; Lescrever;

\section{ABSTRACT}

The article rehearses theoretical alternatives in relation to official documents of recent years, such as Decree No. 9,765, of April 11, 2019, the Common National Curriculum Base and the formulations of the National Pact for Literacy at the Right Age, which replaced the concept of literacy those of literacy, literacy and literacy, with the intention of pointing out that the core of the concept of literacy remains in the three documents (that of phonological awareness), although they were born by divergent political forces; divergences would not be nuclear, but peripheral; the concept of literacy and literacy adapted to Brazilian pedagogy, the reduction and restriction of the concept of literacy and the proposal to revitalize another, that of lecto-writing, and the creation of others: read and write, in agglutinated words; the questioning of the hegemony of the concept of alphabetic written language; the written language in the digital environment, the alphabetic methods and the phonological awareness; the language written in the digital medium derived from typography and the concept of character; digital writing, built with characters, their gestures and supports and, finally, poly-talented children and their refusal of ways of thinking and using instruments, supports and gestures frozen in another historical time. Thus, the article breaks the consensus by contesting the predominantly alphabetic nature of writing and assuming that of graphic awareness in a digitalized world and suggests, in the wake of French scholars, lescrever and leiturescript, concepts that merge the acts with the writing in a single word .

Keywords: Graphic awareness; Reading written; Lescrever; 


\section{Introdução}

Alguns cenários no campo da alfabetização se desenharam no final da segunda década e são redesenhados no início da terceira do século XXI por forças que lutaram entre si e continuam a se enfrentar nos universos ideológicos que vão da esquerda à extrema-direita. Não é possível promover abordagens ao tema sem desnudar, ainda que de forma apressada, os conflitos ideológicos que dão origem a teorias e práticas pedagógicas. Este artigo não foge a este desafio.

Desde o final dos anos 1980, depois da agonia da ditadura civil e militar que asfixiou os estudos da pedagogia brasileira, não havia mais a necessidade de o pesquisador na área da educação marcar ideologicamente o lugar no espectro ideológico de onde escreve e de onde ancora suas ideias para, daí, analisar políticas, teorias, práticas e programas governamentais. Nesta terceira década, posicionar-se contra atos fascistas se tornou novamente necessário.

Apesar de este artigo ter sido elaborado em 2020, a necessária visão histórica das lutas na área da alfabetização devem recuar no tempo para fazer referências aos programas governamentais, como o Plano Nacional da Alfabetização pela Idade Certa (PNAIC), no governo Dilma Roussef (2012-2016), um pouco mais à esquerda, e da Base Nacional Comum Curricular (BNCC), com início de elaboração nesse mesmo governo e conclusão no seguinte, situados à direita e à extrema-direita, resultantes de golpe/impeachment em 2016 e de eleições em 2018. Nesse cenário, um movimento parlamentar de direita apoiado por pesquisadores nacionais e internacionais produziu em 2005 (CAPOVILLA, 2005) um documento em defesa do método fônico e, obviamente, contra o construtivismo que vinha, desde o governo FHC (1994-2002) ocupando os documentos federais, com continuidade no governo Lula (2003-2011).

À análise desses cenários se seguirão a explicitação da tese que orientará o desenvolvimento da argumentação em defesa de um novo olhar para alfabetização que se afasta das determinações oficiais brasileiras; que refuta a necessidade do desenvolvimento da consciência fonológica - cara também a certos setores da esquerda; que coloca sob suspeita a natureza alfabética da linguagem escrita ocidental e os consequentes métodos e práticas pedagógicas elaborados a partir desse pressuposto supostamente inquestionável; que compreende o impacto na aprendizagem da linguagem escrita dos aplicativos digitais e de sua natureza pansemiótica, hibridizada; que percebe crianças poliatentas, tachadas equivocadamente como portadoras de transtornos. Este cenário resulta de embate entre forças centrífugas (de uma esquerda que ressurge resistente) que lutam contra as centrípetas (de extrema-direita), que camuflam o negro e o vermelho nazifascistas nas cores de estandartes verde-amarelos.

O desenvolvimento do ensaio desenvolverá os temas a seguir relacionados. Análise crítica do Decreto N 9.765, de 11 de abril de 2019, de alguns princípios da BNCC e de formulações do PNAIC, com a intenção de apontar que o núcleo da concepção de alfabetização permanece nos três documentos, embora tenham sido paridos por forças políticas divergentes; as divergências não seriam nucleares, mas periféricas; o conceito de letramento e de literacia adaptados à pedagogia brasileira, a redução e restrição do conceito de alfabetização e a proposta de revitalização de outro, o de lecto-escrita, e criação de outros: leiturescrita e lescrever, em palavras aglutinadas; o questionamento da hegemonia do conceito da linguagem escrita alfabética; a linguagem escrita no meio digital, os métodos alfabéticos e a consciência fonológica; a linguagem escrita no meio digital derivada da tipografia e o conceito de caractere; a escrita digital, construída com caracteres, seus gestos e suportes e, finalmente, as crianças poliatentas e a sua recusa a modos de pensar e de usar instrumentos, suportes e gestos congelados em outro tempo histórico. 


\section{Pnaic, Bncc e Decreto 9.765/19}

Este tópico recorta trechos de documentos do PNAIC, da BNCC e do Decreto Federal n. 9765 de 2019 com a intenção de desvelar o núcleo para o qual convergem, apesar de terem sido elaborados em governos de esquerda, de direita e de extrema-direita. O objetivo é evidenciar que as divergências não estão no núcleo teórico, porque as três defendem o princípio do desenvolvimento da consciência fonológica como pré-requisito para a alfabetização, mas que estão diluídas em aspectos metodológicos, recortes teóricos não alinhados entre si, recomendações mais ou menos dogmáticas e defesa ou não de métodos. O debate entre as fileiras de esquerda se perde entre metodizar e não metodizar o ensino porque não coloca em dúvida as concepções fundantes a respeito da natureza da linguagem escrita e a sua (in)dependência em relação à linguagem falada ou a uma língua oral artificialmente padronizada.

O fascículo do PNAIC identificado como Ano 2, Unidade 3 - A apropriação do sistema de escrita alfabética e a consolidação do processo de alfabetização - se apoia no pensamento de teóricos construtivistas, e destaca a relevância de alguns conceitos, entre os quais, o de consciência fonológica. Alguns trechos são aqui recortados e comentados com o intuito de revelar um quadro eclético que defende o conceito de consciência fonológica, embora conteste o do método fônico:

A escrita alfabética não é um código que simplesmente transpõe graficamente as unidades sonoras mínimas da fala (os fonemas), mas, sim, um sistema de representação escrita (notação) dos segmentos sonoros da fala (FERREIRO, 1995; MORAIS, 2005). Trata-se, portanto, de um sistema que representa, que registra, no papel ou em outro suporte de texto, as partes orais das palavras, cabendo ao aprendiz a complexa tarefa de compreender a relação existente entre a escrita e o que ela representa (nota). [...] Desse modo, a apropriação da escrita alfabética deve ser concebida como a compreensão de um sistema de notação dos segmentos sonoros das palavras e não como aquisição de um código que simplesmente substitui as unidades sonoras mínimas da fala. (BRASIL, 2012, p. 6).

A negação da concepção de língua escrita como código de transcrição - a mesma tese de Ferreiro (1995) e aqui assumida pelos autores - abre o caminho para a sua assunção como sistema de notação da fala. Fala aqui parece não corresponder ao conceito saussuriano, mas o de palavras vocalizadas, constituídas por matéria ou por elementos sonoros ou por segmentos sonoros que seriam representados por notações não bem esclarecidas - se grafemas, se letras, se sílabas com letras ou caracteres. Como seria um sistema - não um código - haveria certo grau de complexidade que somente o aprendiz poderia compreender, mas o docente não saberia explicar. Uma vez que o pilar que sustenta o argumento é o do registro gráfico dos mínimos elementos da língua oral, é preciso, para não se deixar contaminar pela pregação do método fônico, rever essas relações para ampliar o conceito de consciência fonológica, porque, tanto em uma posição teórica, quanto na outra, a consciência dos elementos vocais assume o papel central.

A relação mais importante estaria entre elementos materiais sonoros e materiais gráficos, e a menos importante entre o que é imaterial, isto é, entre os sentidos criados na relação pensamento e linguagem, objetivados na linguagem escrita. Ao assumir a nomenclatura de Sistema de Escrita Alfabética (SEA), os autores do PNAIC estabelecem a distinção entre ele e Código de Escrita Alfabética (CEA). Embora na vocalização sonora a sigla não aponte distinção, é na escrita que ela vai ser evidenciada por meio do caractere S ou do C. Essa marca distintiva sinaliza que o sistema gráfico desobedece a certas regras que o submetem aos elementos orais e adquire traços de uma identidade própria. 
Se o leitor não aciona os olhos, não percebe a distinção de sentido entre SEA e CEA, porque para os ouvidos não há distinção. A mesma coisa se daria, então, com as demais palavras, o que contraria o próprio conceito de consciência fonológica, porque nele a criança não poderia se fiar para escrever as duas siglas. O documento, entretanto, afirma que:

Tanto para o processo de apropriação do SEA como para as consolidações das correspondências som-grafia, o desenvolvimento de habilidades de reflexão fonológica (consciência fonológica) é importante. O que é, então, consciência fonológica? A consciência fonológica consiste na capacidade de refletir conscientemente sobre as unidades sonoras das palavras e manipulá-las de modo intencional (GOMBERT, 1990; FREITAS 2004; MORAIS, 2006). (BRASIL, 2012, p. 9).

A definição do que seria a consciência fonológica - pilar ou pré-requisito para uma criança se alfabetizar - não se distancia de outras tendências não construtivistas em alfabetização, notadamente a que por décadas investiu política e economicamente em setores dos três poderes da cambaleante república brasileira. Mas como não poderia haver identificação de princípios em grupos politicamente e ideologicamente tão distintos, seria necessário criticar um certo reducionismo do conceito para abrir espaços para sua ampliação. Desse modo, os vendedores do método fônico seriam os possuidores do conceito restrito e os autores do PNAIC ficariam com a outra parte, a mais ampliada, e, por essa razão, com outro conceito cuja distinção necessitaria ser claramente marcada:

É preciso esclarecer, portanto, que "consciência fonológica" não é sinônimo de "consciência fonêmica" ou de "método fônico", uma vez que o que consideramos como "consciência fonológica" é mais abrangente que a consciência fonêmica, envolvendo não apenas a capacidade de analisar e manipular fonemas, mas também, e sobretudo, unidades sonoras como silabas e rimas.). (BRASIL, 2012, p.10). O método fônico é um método tradicional de alfabetização que toma como ponto de partida o fonema, que, combinado a outros fonemas, por meio de um processo de síntese, constitui sílabas e palavras. (BRASIL, 2012, p.10).

A distinção resta, então, bem marcada: um se preocupa com os fonemas - entidade abstrata impossível de ser apreendida - mas também com outras unidades que não o fonema, as maiores, as sílabas, algo que não seria propriamente uma unidade, mas segmentos vocalizados. O método fônico - CEA - assumiria o fonema como unidade (ou elemento). Mas o SEA consideraria também o fonema - entidade abstrata não manipulável. A distância entre um e outro é tão curta que os leva a se confundirem, apesar de a intenção declarada ser a distinção. O que soa um pouco contraditório é a discussão de métodos ou modos de alfabetizar, isto é, de ensinar a linguagem escrita, tomar como referência a composição de fonemas de uma língua oral padronizada em vez de a linguagem oral com seus alofones. Mesmo assumindo o conceito de escrita como representação e o princípio de fonetização desenvolvidos pelo construtivismo, o documento entra em colisão com Ferreiro (2004) ao insistir na essencialidade da consciência fonológica. No PNAIC:

Para compreender que a escrita representa (nota) os segmentos sonoros das palavras e não os significados a ela relacionados, o desenvolvimento de habilidades de reflexão fonológica é essencial. Em outras palavras, para ingressar no que Ferreiro (1995) denominou de "período de fonetização da escrita", que se inicia no nível silábico e culmina no alfabético, a criança precisará, necessariamente, desenvolver capacidades de reflexão fonológica, estabelecendo relações entre a escrita e a pauta sonora, por meio, por exemplo, da segmentação de palavras orais em sílabas e da comparação de palavras quanto ao tamanho e às suas semelhanças sonoras. (BRASIL, 2012, p.10-11). 


\title{
Em Ferreiro:
}

\begin{abstract}
A maioria das pesquisas sobre phonological awareness sustenta, implícita ou explicitamente, uma noção da escrita como codificação das unidades da oralidade. [...] essa ideia aplicacionista (do ponto de vista psicolinguístico) implica uma ideia de pré-requisitos, em termos pedagógicos, e uma ideia reducionista, em termos epistemológicos. As unidades mínimas da escrita (as letras) só são concebíveis por redução a unidades mínimas preexistentes na língua oral. Toda ideia de interação entre unidades prévias - fônicas, mas não necessariamente fonológicas - e unidades gráficas, que permita o surgimento de uma nova unidade não pré-existente, é alheia a essas proposições estáticas, reducionistas e lineares. (FERREIRO, 2004, p. 137) Estamos sugerindo - com consciência do atrevimento - que o fonema não preexiste à "tomada de consciência". O fonema é produto de um novo nível de reorganização das unidades da fala, permitido (sugerido, imposto talvez) pela escrita. (FERREIRO, 2004, p. 148).
\end{abstract}

Ferreiro sugere que a consciência do fonema é dada pela letra, isto é, são as unidades escritas que dão os contornos às unidades da oralidade, por isso não há defesa da essencialidade da consciência fonológica. Admitindo o caráter essencial do desenvolvimento da consciência fonológica para que uma criança aprenda a escrever, o PNAIC também admite a insuficiência de sua ação como mediadora do processo. A insuficiência seria suprida por uma operação lógica entre totalidade e partes constitutivas. Resta, contudo, uma indagação. Essa lógica seria construída pela criança para estabelecer relações entre partes constitutivas da palavra da língua oral (como parece indicar o trecho da citação) ou para compreender palavras escritas organizadas em enunciados borbulhando de sentidos? O olhar para um lado e para o outro da aparente controvérsia não encontra senão distinções periféricas entre o método fônico e os princípios expostos no PNAIC. O que há são convergências no núcleo.

Resultante de luta entre forças que se situavam em campos não muito distantes entre si, a redação da Base Nacional Comum Curricular, especificamente na Alfabetização, deixa sinalizadas algumas marcas desses confrontos reveladas por alinhavados nem sempre harmônicos. Os trechos abaixo foram selecionados têm a intenção de apontar os traços de teorias que deram suporte ao PNAIC, de teorias de organizações não acadêmicas abrigadas no governo responsável pelo golpe aplicado ao governo Dilma Roussef em 2016, e de teorias que alimentam o decreto federal expedido pela extrema direita pós-golpe. Sutis concessões são feitas aqui e ali, mas o núcleo central de base não se altera: o conceito de consciência fonológica continua inabalável e, por isso, une teorias aparentemente divergentes. Coloco em itálico o advérbio aparentemente porque na essência são mesmo convergentes: as divergências são cosméticas.

Ao situar o processo de alfabetização prioritariamente no início do ensino fundamental, o documento expõe claramente suas bases: ações mecânicas, codificação e decodificação de fonemas e grafemas, consciência fonológica, segmentação silábica e uso de formas diversas de letras:

Nesse processo, é preciso que os estudantes conheçam o alfabeto e a mecânica da escrita/leitura - processos que visam a que alguém (se) torne alfabetizado, ou seja, consiga "codificar e decodificar" os sons da língua (fonemas) em material gráfico (grafemas ou letras), o que envolve o desenvolvimento de uma consciência fonológica (dos fonemas do português do Brasil e de sua organização em segmentos sonoros maiores como sílabas e palavras) e o conhecimento do alfabeto do português do Brasil em seus vários formatos (letras imprensa e cursiva, maiúsculas e minúsculas), além do estabelecimento de relações grafofônicas entre esses dois sistemas de materialização da língua. (BRASIL, 2019, p. 89-90). 
PNAIC e BNCC se encontram no mesmo ponto da essência do seu paradigma - a tomada de consciência fonológica com todos os seus desdobramentos e consequências daí derivadas. Embora gestadas em momentos políticos distintos, os mesmos princípios se mantiveram porque espelham pesquisas oriundas das áreas da fonoaudiologia, da neurociência, da psicologia cognitiva, e da fisiologia, consideradas as que apontam evidências científicas, argumento que seria aplicado também no decreto de 2019. A descrição segura do trecho acima se contamina com incertezas logo em seguida, porque os sistemas e as premissas não funcionam como leis. Não podem ser aplicadas, porque alguns aspectos do objeto - o sistema de escrita alfabético do português no Brasil - não se submetem a essas leis, porque os fonemas já não seriam manipuláveis, mas supostamente os seus alofones, indicadores de registros linguísticos de pronúncia.

Dominar o sistema de escrita do português do Brasil não é uma tarefa tão simples: trata-se de um processo de construção de habilidades e capacidades de análise e de transcodificação linguística. Um dos fatos que frequentemente se esquece é que estamos tratando de uma nova forma ou modo (gráfico) de representar o português do Brasil, ou seja, estamos tratando de uma língua com suas variedades de fala regionais, sociais, com seus alofones, e não de fonemas neutralizados e despidos de sua vida na língua falada local. De certa maneira, é o alfabeto que neutraliza essas variações na escrita (BRASIL, 2019, p. 90).

Ainda mais: por serem os fonemas e seus alofones incontroláveis, recorre-se a um estratagema: a neutralização de suas manifestações. Em outras palavras, eliminam-se as diferenças por meio de um registro gráfico unificado com o uso da letra (curiosamente, não pelo sistema gráfico!). A contradição na argumentação parece anunciar-se. Na essência, não basta isolar fonemas (porque nem são isoláveis) nem seus alofones (que de fato se manifestam na oralidade) porque é preciso ensinar e aprender a escrever e a ler o sistema gráfico, uma organização inteligente que anularia a sua suposta própria referência - os sons:

Mencionamos a primeira relação ao dizer que a criança está relacionando com as letras não propriamente os fonemas (entidades abstratas da língua), mas fones e alofones de sua variedade linguística (entidades concretas da fala). (BRASIL, 2019, p. 91).

Se a construção gráfica dos enunciados anula as divergências, pode-se deduzir que o sistema gráfico se desvencilha do jogo confuso da oralidade para adquirir vida própria, alimentada pelos caracteres gráficos que o compõem. Longe dessa hipótese, a BNCC admite que as leis não são de fácil aplicação e lança uma leve crítica aos manuais, mas, na essência, com eles se confunde:

Dito de outro modo, conhecer a "mecânica" ou o funcionamento da escrita alfabética para ler e escrever significa, principalmente, perceber as relações bastante complexas que se estabelecem entre os sons da fala (fonemas) e as letras da escrita (grafemas), o que envolve consciência fonológica da linguagem: perceber seus sons, como se separam e se juntam em novas palavras etc. Ocorre que essas relações não são tão simples quanto as cartilhas ou livros de alfabetização fazem parecer. Não há uma regularidade nessas relações e elas são construídas por convenção. (BRASIL, 2019, p. 90).

Por fim, tenta demarcar seu campo para não se sentir ameaçada pelo método fônico, mas as fronteiras já rompidas não permitem distanciamentos e separações, porque as recomendações aos docentes alfabetizadores se tocam no núcleo: os elementos menores da construção da palavra oral devem ser representados na palavra e no enunciado gráficos: 
Pesquisas sobre a construção da língua escrita pela criança mostram que, nesse processo, é preciso:

- perceber quais sons se deve representar na escrita e como;

- construir a relação fonema-grafema: a percepção de que as letras estão representando certos sons da fala em contextos precisos;

- perceber a sílaba em sua variedade como contexto fonológico desta representação;

- até, finalmente, compreender o modo de relação entre fonemas e grafemas, em uma língua específica. (BRASIL, 2019, p. 91).

Afinal, a face visível e material da palavra gráfica não é considerada importante no início da aprendizagem, nem como nuclear, mesmo sendo a condição primeira de seu reconhecimento como signo pleno no processo de objetivação do enunciado e de sua compreensão no ato de ler. O traço de identidade visual da palavra é desconsiderado e diluído ao longo de toda a escolarização fundamental: "É preciso também ter em mente que este processo de ortografização em sua completude pode tomar até mais do que os anos iniciais do Ensino Fundamental." (BRASIL, 2019, p. 93).

Vou tentar demonstrar que a ortografia - a composição sempre atualizada do signo gráfico - revela as unidades gráficas de composição do todo, isto é, do próprio signo, e do enunciado, também um todo, no universo do todo dos gêneros dos enunciados. Em virtude de seu caráter identitário, o papel da composição gráfica não pode ser postergado, sob o risco de essa função ser ocupada pelos elementos orais que não compõem, materialmente, a linguagem escrita.

Meu intuito é apontar as congruências em torno da necessidade de consciência fonológica, encontradas nos documentos oficiais elaborados em governos situados em espectros distintos do universo macropolítico. Em 2019, o primeiro ano depois de a extrema-direita chegar ao governo por meio de eleições, foi publicado um Plano Nacional de Alfabetização, cujos princípios estão no Decreto 9.765/19. Pretendo dar destaque a alguns itens do art. $2^{\circ}$ que esclarece conceitos que serão objeto de aplicação e que se aproximam dos dois documentos anteriores aqui analisados: "Considera-se: "IV - consciência fonêmica - conhecimento consciente das menores unidades fonológicas da fala e a habilidade de manipulá-las intencionalmente;" (BRASIL, 2019). Para distanciar-se, de algum modo, dos documentos anteriores, os idealizadores do Decreto não assumem a expressão consciência fonológica, substituída por consciência fonêmica, mas que inclui conhecimento consciente das menores unidades fonológicas da fala e habilidade de manipulá-las intencionalmente.

A tentativa de distanciamento parece não obter resultados, porque o conceito é o mesmo, tanto no PNAIC, quanto na BNCC, quanto neste Decreto. O item seguinte, o V, sugere a metodologia de ensino: $V$-instrução fônica sistemática - ensino explícito e organizado das relações entre grafemas da linguagem escrita e os fonemas da linguagem falada. Nada de novo, porque os documentos anteriores também destacam a necessidade imperiosa de ensinar a correspondência entre elementos de sistemas diferentes após o domínio da capacidade de manipular apenas os elementos de um deles: o sistema sonoro. O item VI dedicado ao ato de ler segue a mesma toada, o de elevar ao ápice a sonorização das unidades silábicas com velocidade como o ponto de chegada: VI - fluência em leitura oral - capacidade de ler com precisão, velocidade e prosódia. O real ponto no horizonte de orientação para o ato de ler - a compreensão - é substituído pela velocidade que, supostamente, produziria sentido a posteriori. Estaria, como a ortografia, diluída como objeto ao longo dos anos do ensino fundamental. 
Por fim, há outro ensaio para estabelecer distanciamentos. Em vez de tomar para si o conceito de letramento, já apropriado por tendências que construíram o PNAIC, os teóricos do governo de 2019 tomam de empréstimo o termo literacia usado em Portugal e Espanha, que equivalem ao literacy do inglês e ao litteratie do francês, e ao de letramento no Brasil. A influência de alguns teóricos portugueses, defensores de longa data do método fônico, explica a escolha de uma mesma palavra, com o mesmo conceito, com distinções tão-somente de elementos fonéticos e gráficos. Essas escolhas por distinções superficiais, como fonêmica e literacia em vez de fonológica e letramento, não marcam divergências, mas convergências. Na essência, o núcleo conceitual de ensinar e de aprender a ler e a escrever continua intocado. Apesar das divergências políticas, há a subserviência geral aos princípios de pesquisa no campo da fisiologia humana, do caminho percorrido por elementos sonoros e visuais pelos nervos, neurônios e zonas cerebrais do homem, e da necessidade de ensinar às crianças de 2020 o princípio grego de constituição de uma escrita predominante alfabética nos seus primórdios, como se nem o sistema de escrita, nem as crianças, nem a sociedade tivessem sofrido desorganizações e reorganizações ao longo de séculos e de milênios.

\section{Caminhos de escape}

O ponto de partida para enfrentar essas configurações humanas na composição de suas relações no tecido social terá de ser deslocado radicalmente. Em vez de considerar a materialidade da linguagem oral, isto é, seus elementos constitutivos como ponto de referência para a aprendizagem da escrita, será necessário encontrar a relação entre oralidade e escrita não nos elementos materiais fonemas e grafemas - mas nos sentidos por elas trocados e deslocar o ponto central da materialidade para os caracteres que compõem as palavras em enunciados. Por isso, este artigo, já na metade de sua elaboração, destaca que defende a tese de que os modos de ensinar e de aprender a linguagem escrita no processo de alfabetização podem se distanciar da concepção de que a linguagem escrita latina ocidental continua organizada sob princípio alfabético desde sua gênese e, consequentemente, da necessidade de desenvolvimento da consciência fonológica como referência. Ao disso se distanciar, a tese se aproxima do conceito de linguagem escrita híbrida, pansemiótica, que demanda novos modos de pensar, novos suportes, novos gestos, novos instrumentos de inscrição, em relações profundamente dialógicas.

Por isso tem início aqui a análise das relações estreitas entre herança tipográfica, dispositivos digitais em transformação e aplicativos usados em troca de mensagens. As análises partem do princípio de que a escrita no mundo digital recupera marginalizados contrapontos históricos feitos a uma concepção de escrita apoiada integralmente no princípio alfabético. O homem, com a escrita digital, reintroduz o componente logográfico, historicamente desprezado em virtude da predominância do princípio alfabético, e recria um conjunto híbrido, concretamente manifesto em trocas instantâneas de mensagens. Novos gestos, novos instrumentos, novos suportes e escrita revitalizada organizam novas relações entre os que ensinam, os objetos a serem ensinados, e os que aprendem. Anuncia-se como fundamental encontrar um outro conceito, para que escapemos das armadilhas dos tantos conceitos de letramento e dos de literacia, no cenário brasileiro, diferentes na forma gráfica e sonora, mas convergentes em seus sentidos. Ao fazer isso, nos aproximamos de núcleos de resistência onde se encontram estudiosos, como Souchier, para quem, na França, a recuperação do termo lettrüre poderia impedir que o termo litteratie, de origem inglesa, ocupasse esses espaços conceituais: 
Maud Sissung explica, a propósito disso, que "a língua francesa não possui equivalente à palavra inglesa literacy, que designa a capacidade de ler e de escrever". Ela acrescenta, porém, que "o francês possui uma palavra para designar" essa habilidade - ou essa "arte" - e especifica que esse termo não era outro senão o famoso "lettrüre", dotado de suas inumeráveis variações gráficas. (SOUCHIER, 2015, p. 212).

A investida contra o conceito de alfabetização há duas ou três décadas reduziu-o a uma visão estritamente técnica, ou seja, restringiu-o aos chamados mecanismos de base que cuidam da correspondência entre fonema e grafema. Reduzido a esse aspecto, alfabetização cedeu lugar a literacyl letramento, que cuida das manifestações usuais da linguagem escrita em vez de lidar apenas com questões técnicas. O Decreto reviveu este conceito, mas o considera literacia, ou seja, letramento. Melhor seria se o chamasse de alfabetização, pura e simples, mas isso se chocaria com a expressão largamente utilizada em estudos brasileiros - alfabetizar/letrando, isto é, ensinar os mecanismos de base e ao mesmo tempo ensinar os usos da linguagem escrita. Mesmo querendo se distanciar um do outro, ironicamente se reencontram.

Souchier (2015) recusa a substituição de alfabetização por literacy/literacia/litteratie. Prefere recuperar, como vimos, o termo medieval lettrüre, embora a avalanche midiática não Ihe tenha dado espaço. As ações humanas nas mídias informatizadas (SOUCHIER, CANDEL e GOMEZ-MEJIA, 2019) exigem a fusão dessa ação dupla de ler-escrever, inseparável nos dispositivos, mas possível ainda fora deles. Esses autores observam que "Quando escrevo em meu teclado, eu estou igualmente mergulhado em uma atividade de leitura. Eu leio as teclas como também os signos conexos, como também eu posso ser levado a ler as instruções na tela". (SOUCHIER, CANDEL e GOMEZ-MEJIA, 2019, 25). Para eles, a humanidade vive uma sociedade de profunda textualização, graças aos dispositivos e aplicativos digitais. Nesse fenômeno de textualização essas ações duais aglutinadas roubam o cenário e se metem vivamente nas relações humanas. Os conceitos de literacia, de litteracy e de letramento não têm ferramentas para compreender e para explicar a totalidade do processo, porque as relações humanas, por meio desses dispositivos que redimensionam a linguagem escrita, são muito mais complexas:

A atividade de escrita e de leitura - a lettrüre - se revela então ser uma prática infraordinária pela qual nós não temos por costume nos colocar a pensar. Ela nos permite, todavia, ter acesso a todo o leque de mídias informatizadas colocadas em movimento. Emblemática de nossas práticas de comunicação contemporâneas, ela se inscreve em uma história longa e requer uma aprendizagem específica [...]. Longe de ser de um gesto puramente técnico, essa habilidade, essa arte de lettrüre leva em conta uma verdadeira cultura letrada que supõe uma economia e uma organização específica da sociedade. (SOUCHIER, CANDEL e GOMEZ-MEJIA, 2019, p. 41. Grifos do autor).

Acompanho o pensamento dos três pesquisadores e as suas razões para assumir um novo conceito, mais adequado para as ações dos homens e das crianças nos dispositivos digitais, que se afasta do conceito de literacia e de letramento, para aproximar-se mais do de lecto-escrita do construtivismo, e se aninhar em conjunto único e indissociável em português - leiturescrita, semelhante a lectoescrita referenciado por Souchier no mundo hispânico da América do Sul, mas, como penso nos atos praticados com ela, sugiro lescrever. Estes atos indissociáveis não se manifestam do mesmo modo em outros suportes: "Eu escrevo em um teclado e leio na tela. Na realidade, minha atividade é um pouco mais complexa, porque eu me situo permanentemente em uma configuração dual de escrita-leitura, de lettrüre" (SOUCHIER, CANDEL e GOMEZ-MEJIA, 2019, p. 24). 
Ao reintroduzir um termo tipicamente francês no universo dos estudos sobre linguagem, Souchier (2015) destaca as práticas de ler e de escrever, quase simultâneas, nos aparelhos digitais. Com isso, recusa-se a usar também letramento digital e outros letramentos, derivados do conceito inicial. Aqui, por opção, também não uso o conceito nem o termo letramento, mas recupero o termo espanhol usado por Ferreiro (1995) - lecto-escrita e o adapto para o português como leiturescrita, sem hífen, como um só termo com um novo conceito, aproximado ao de lettrüre, com todos os sentidos amplos que ele carrega, porque não reconheço a importância das relações fonema/grafema. Letrüre, entretanto, funde os atos de ler e de escrever, por isso sugiro lescrever, dois atos fundidos em uma só palavra. A leiturescrita no mundo digital é reinventada porque a linguagem escrita abandona o controle de supostas leis do mundo das escritas alfabéticas para assumir seu hibridismo, com as configurações visuais semióticas exigidas pelos aplicativos em celulares, notadamente os de troca de mensagens. A esse respeito, assim se manifestam Souchier, Candel e Gomez-Mejia (20019, p.14):

No mundo hispânico, a lectoescrita inicial é a expressão que cobre o período de aprendizagem da leitura e da escrita entre as crianças (período geralmente situado entre 3 e 6 anos). Associa-se assim sob a mesma expressão um período dedicado à aprendizagem das atividades de leitura e de escrita reunidas sob um mesmo gesto físico e intelectual. Os anglófonos utilizam o termo literacy, que corresponde igualmente aos saberes de um mesmo gesto. A leitura, a escrita e os saberes inscritos na tradição lettrée (letrada) se reencontra sob esse termo que terminou por ser afrancesado em littératie depois da circulação dos trabalhos do antropólogo Jack Goody (2007).

Antes e depois das aulas, as crianças manipulam em casa os teclados virtuais dos celulares para escolher e fazer avançar as etapas dos jogos, para ver a performance de um youtuber, para ler um recado da mãe ou do pai ou da avó ou do avô, ausentes, pelo WhatsApp. As crianças praticam o ato conjunto de lescrever mapeado na citação e, por isso, o ensino metódico de exercícios para desenvolvimento de consciência fonológica as levam ao tédio, do mesmo modo quando na escola Ihes ensinam antigas lições, de morrer pela pátria e viver sem razão (VANDRÉ, 2020). Esse conjunto afastado da realidade da vida leva os alunos ao distanciamento da linguagem escrita, dos novos suportes, dos novos gestos e os empurra para o reino dos transtornos de comportamento.

Por isso, este estudo analisa as relações estreitas entre herança tipográfica, dispositivos digitais em transformação, e aplicativos usados em troca de mensagens. As análises partem do princípio de que a escrita no mundo digital recupera marginalizados contrapontos históricos feitos a uma concepção de escrita apoiada integralmente no princípio alfabético. O homem, com a escrita digitalizada, reintroduz o componente logográfico, historicamente desprezado em virtude da predominância do princípio alfabético, e cria um conjunto híbrido, concretamente manifesto em trocas instantâneas de mensagens.

Se a escrita pode ser reconhecida no mundo digital de 2020 como não predominantemente alfabética, como então era em seu nascimento entre os gregos, não há razão alguma para que sejam aplicados métodos, como o fônico, nem o conceito de SEA, nem o de consciência fonológica. Considerar a escrita não estritamente alfabética fere mortalmente o princípio sobre o qual se apoiam todas as tendências com presença em documentos oficiais aqui referenciados: PNAIC, BNCC, Decreto 9765, e concepções como alfabetizar-letrando. O mundo digital aponta para um outro futuro, porque foi desnudada, pelo uso digital, a natureza não alfabética da linguagem escrita e a necessidade de reconhecer a autonomia dela em relação ao oral: 
Este desejo de redefinir o signo escrito e de dar autonomia ao escrito foi realizado pela abertura a outras disciplinas ou paradigmas de pesquisa, a fim de extrair argumentos suscetíveis que pudessem estabelecer uma semiologia do escrito, até mesmo uma linguística do escrito, em bases mais específicas e mais amplas.

Diante dos defensores dessa concepção restrita, para os quais a escrita tem por única função semiótica a de notar a linguagem oral e que nega a ela a sua autonomia, desenvolveu-se um ponto de vista oposto: a abordagem mais ampla e integracional ( $R$. Harris) ou "pansemiótica" (KLOCK-FONTANILLE, 2016, p. 6).

Klock-Fontanille reconhece o distanciamento do escrito em relação ao oral e, em consequência, a conquista de sua autonomia. O olhar para a escrita como uma linguagem autônoma abre caminhos paradigmáticos pouco trilhados porque rompe com um modo de pensar que anula suas propriedades intrínsecas, quando compreendida como um sistema de notação da oralidade, tal como está implícito no Sistema de Escrita Alfabética (SEA) exposto no PNAIC. Por isso Klock-Fontanille anuncia a possibilidade de "abertura a outras disciplinas ou paradigmas de pesquisa". Trata-se, por isso, de encontrar outro paradigma diverso do lugar comum explorado até aqui. Outra antropóloga, Krämer (2016), anuncia que houve debates sobre o tema no final do século XX que não atraíram interesse, porque sacudiam radicalmente o pensamento conservador:

É justamente o debate sobre "Oralidade e Alfabetização" no último terço do século passado que revelou a criatividade da alfabetização e que colocou o escrito sobre um plano de igualdade com a fala. Desde então, o oral e o escrito são considerados como formas relativamente autônomas da língua, cada uma apresentando os desempenhos próprios de um ponto de vista de mídia, linguístico, cultural e antropológico. (KRÄMER, 2016, p. 1).

Conquistada a igualdade entre as duas formas, em vez de uma ser da outra escrava, é possível vislumbrar em todas as áreas do conhecimento a ruptura com o pensamento restritivo e limitante que, para se manter, inibe pesquisas e assume a visão de escrita alfabética e de seu ensino metodizado como um dogma inabalável. A escrita, vista como um conjunto composto por unidades materiais caracteres imagens e palavras-imagens - e pelos sentidos, pode provocar a ruptura do dogma fonográfico:

O conceito de Schriftbildlichkeit visa a uma revisão do "dogma fonográfico". A escrita não é mais considerada como uma forma da língua, mas como um híbrido de língua e de imagem. Mas por que uma revisão da concepção fonográfica da escrita e assim levar em conta a "natureza icônica" das escritas é absolutamente necessária? Por que é um problema considerar as escritas como forma de língua? (KRÄMER, 2016, p. 3).

As duas perguntas finais de Krämer insistem na necessidade de aprofundar o debate iniciado no final do século passado e é, em razão dessa necessidade e do cenário sócio-cultural desenhado pelo uso dos celulares e dos seus aplicativos neste século, que a concepção do objeto a ser em ensinado pode ser revista e a metodologia de ensino reorganizada. O princípio alfabético não mais ditaria, por isso, as regras da didática da alfabetização ou, melhor, da didática do ensino do ato conjunto de lescrever.

Quando Freinet (1976) ensinava os seus alunos a manipular os caracteres para montar no componedor o texto do jornal da classe que circularia em Saint Paul de Vence, disseminava entre eles a ideia de que o signo verbal tinha sentidos que deveriam ser materializados em uma configuração convencionalmente respeitada e, ainda mais, desenvolvia, à semelhança da manipulação dos sons 
da oralidade, a ideia de que sentidos poderiam ser materialmente objetivados com a montagem e reposicionamento de posições dos caracteres na configuração da palavra. Essa ideia se contrapunha, desde então, à de subserviência dos caracteres gráficos aos elementos orais. Se havia uma consciência fonológica para manipular sons de acordo com os sentidos, haveria também uma consciência gráfica em formação, na leiturescrita, para manipular caracteres. A consciência gráfica, nascida com a tipografia, daria autonomia à linguagem escrita e faria de seus caracteres as unidades de sua constituição. A manipulação da face visível e gráfica do signo recuperaria a iconicidade abandonada da linguagem escrita, mas não perdida, ao longo dos séculos. Em vez de letras, a tipografia ensinava que o homem escrevia com caracteres, entre eles, o espaço branco, usando as mãos e todos os dedos, com gestos pouco usuais no interior de uma sala de aula. Ali se inaugurava uma nova era. Mas um toldo imenso a cobriu e a cobre até hoje. Ela ainda espera seu reconhecimento, mas somente em salas de aula, porque na vida diária movida a aplicativos nos celulares, a linguagem escrita híbrida, icônica, com caracteres, e promotora da consciência gráfica, explode criativa e decisiva nos atos humanos.

A tipografia escolar freinetiana passou por um processo de miniaturização e se instalou, com muito mais recursos, e com muito maior poder de promover a divulgação dos escritos, nos celulares por meio de seus aplicativos. A linguagem escrita híbrida e digitalizada (BOUCHARDON, 2017) ainda não entrou metodologicamente nas escolas, mas entrou na vida das crianças que manipulam os aparelhos dos pais em casa. Os aplicativos de trocas de mensagens, como o WhatsApp, se utilizados pelas crianças, criam as seguintes possibilidades: a) permitem a tomada de consciência de que a linguagem escrita, historicamente elaborada para ser olhada, é um instrumento de trocas culturais; b) permitem às crianças entender o papel dos signos visuais na mediação das relações humanas; c) promovem o desenvolvimento da consciência gráfica, porque as crianças manipulam com os polegares as teclas virtuais representantes de caracteres, que ultrapassam o conceito simplório de escrever com letras e de que letras seriam organizadas em conjunto silábico; d) destacam a configuração visual das palavras; e) permitem o uso das abreviações e abreviaturas e, com isso, se distanciam da obediência à sequência sonora e percebem a autonomia das unidades da escrita em relação às orais; f) retiram a aura sagrada da aprendizagem da escrita pelo uso de um mesmo instrumento - o lápis, um mesmo movimento - o de rotação e translação, e um mesmo suporte - o papel; g) destroem a necessidade de desenhar o caractere na página, porque as letras estão já prontas para as escolhas pelos dedos; h) sugerem as palavras com a ortografia consagrada armazenadas nos bancos de dados, que se tornam modelos para a compreensão do sistema gráfico.

A escrita digitalizada estreita os laços com a sua mãe - a escrita tipográfica, de um lado, e de outro reforça os argumentos para a elaboração de uma teoria da linguagem escrita, com elementos, modelos, usos, gêneros, circulação, ensino e aprendizagem autônomos em relação a seus correspondentes na linguagem oral. O vínculo entre as duas continua sendo mantido pelos sentidos compartiIhados, mas não mais pelos aspectos tangíveis da materialidade.

Em seus estudos sobre a linguagem escrita, o escrever e o ler, Richaudeau (1999) um intelectual francês com pés fincados no desenvolvimento da tipografia, traça a evolução, lenta antes do século XIX e rápida depois dele, da imprensa e das formas de inserção dos caracteres sobre os suportes. Pretendo incluir aqui algumas de suas informações e de suas análises.

Ele situa na Alta Idade Média o trabalho do monge-leitor que, diante dos manuscritos em scripta continua, sem espaços e sem pontuação, deveria "decifrar e articular cada sílaba e, de algum modo, tomar consciência do texto o escutando, 'lendo com os lábios', mas com imprecisão de fonemas, porque "aos mesmos grupos de letras correspondiam a sons diferentes, e assim as abreviações muito 
frequentes 'quebravam' esse processo" (RICHAUDEAU, 1999, p. 129). É preciso salientar em suas palavras o comentário sobre as abreviações, já utilizadas, que quebravam, que provocavam ruptura das regras de correspondências e colocavam em xeque o sistema considerado predominantemente alfabético, porque menos letras eram inscritas em relação à quantidade de fonemas. O princípio estava, portanto, rompido.

A linguagem escrita se distanciou de sua subserviência em relação à oralidade quando os monges inseriram o espaço de separação e indicaram o caminho visual para inscrição e percepção dos caracteres, unidades constituidoras do todo, o texto. As letras se tornaram uma categoria restrita no interior de um mundo mais amplo - o dos caracteres. Em 1445, com Gutenberg, veio a imprensa e por quatro séculos nada mudaria na feitura de livros: "os caracteres metálicos reunidos manualmente em linhas, essas linhas empilhadas em páginas, essas páginas impressas sobre folhas de papéis por uma prensa no braço." (RICHAUDEAU, 1999, p. 129). Em 1949, com a fotocomposição, houve uma grande mudança:

a morte do chumbo, substituído pelo filme que elimina todas as servidões e a rigidez da composição metálica. Mas o novo reino tecnológico seria de curta duração com a aparição em 1984 do Macintosh" da jovem firma Apple, seguida de softwares para micros de todas as marcas. (RICHAUDEAU, 1999, p. 130).

Em 1999, Richaudeau, com a visão histórica do desenvolvimento da tipografia, já antevia as mudanças na disposição nos caracteres nas páginas ou na tela do computador, da morte da linearidade e do nascimento de um mosaico de informações. Seus estudos informam que em 1928, "foi publicada a primeira edição de um código tipográfico, com o subtítulo: Escolha de regras para uso dos autores e dos profissionais do livro; e tornou-se uma verdadeira bíblia das pessoas do livro e da imprensa; até hoje intocado em nossos tempos. (RICHAUDEAU, 1999, p.144. Grifo do autor).

Com a intenção de contribuir para a pedagogia do ensino dos atos fundidos de lescrever em um sempre crescendo mundo textualizado pela escrita digitalizada, sugere a ruptura do pensamento linear da escrita manuscrita, e mesmo da escrita tipográfica, para que as crianças se sintam em liberdade para pensar de outro modo:

Em primeiro lugar [...] valorizar em todos os raciocínios (entendido no sentido amplo do termo) por intuição, por analogia, por jogos lógicos. Isso é que conduziria - retomando os termos de Symour Papert - a substituir o 'instrucionismo' tradicional por um 'construcionismo' ativo, uma bricolagem mental e material, pela qual a criança deseja, procura, tateia, se engana, descobre, compreende e memoriza. E que corresponde aos esquemas mentais do labirinto, da espiral, da estrela e do ouroboros (RICHAUDEAU, 1999, p. 146.

Suas recomendações pedagógicas se atritam com as recomendações do PNAIC, BNCC e do Decreto Federal de 2019, golpeiam o âmago de suas premissas e anunciam a ruptura paradigmática que poderá consolidar os rumos de uma nova era na alfabetização. São sete recomendações, das quais destaco três:

[...] a importância fundamental do contexto para a compreensão dos sentidos das palavras e das frases condena as aprendizagens da leitura ditas 'sintéticas' que privilegiam desde o início a percepção fonológica das sílabas depois das palavras, ignorando suas polissemias frequentes, arriscando formar 'leitores' (?) decifradores de sons e ignorantes em significações. 
[...] é um erro considerar a linguagem escrita como uma segunda versão da linguagem oral. E, por via das consequências, de ligar a aprendizagem dessas duas formas de comunicação. E notadamente, deduzir as formas escritas das formas orais.

[...] o código e certas regras tipográficas que datam da era do chumbo, não mais adaptadas à era do tratamento do texto, da PAO e da internet. E seu ensino deve ser renovado por consequência. (RICHAUDEAU, 1999, p. 146-47).

A sua experiência com a tipografia e o seu olhar histórico-tipográfico da escrita abrem, segundo meu ponto de vista, dois caminhos convergentes para a consolidação de um novo paradigma em alfabetização - leituraescrita - e para a aprendizagem das crianças. O primeiro tem a ver com os desdobramentos do desenvolvimento da consciência gráfica anunciada por Foucambert (1998) e aprimorada por Bajard (2014), em oposição à consciência fonológica. O segundo tem a ver com a ruptura linear do modo de pensar. Esse caminho me levaria a entender as crianças como aprendizes poliatentos, isto é, com atenções simultâneas, rápidas, não lineares. Nos parágrafos seguintes introduzo os argumentos e os dados expostos por Foucambert (1998) e Bajard (2014) a respeito do primeiro caminho.

Filiado ao mesmo paradigma conceitual de Richaudeau, Foucambert cunha o conceito de consciência gráfica vinculado a uma consciência linguística que inclui a experiência com a oralidade. Esse novo conceito se apoia, como contraponto, às mesmas descrições atribuídas ao conceito de consciência fonológica, mas, em vez de colocar a gráfica a serviço da fonológica, as separa, já que cada uma se situa em campos diferentes dos estudos de linguagem, a primeira na escrita, a segunda no oral. Se as crianças podem desenvolver consciência fonológica ao pronunciar os elementos sonoros, pode também, de modo distinto, desenvolver a consciência gráfica na manipulação dos caracteres tipográficos que constituem os signos verbais da linguagem escrita. É o que parece conceber Foucambert (1998, p. 128):

Pela descoberta do escrito e pelo esforço em aprender a utilizá-lo, a consciência linguística vai enriquecer-se com uma nova moldura, a consciência gráfica, que a transforma completamente. Que a experiência linguística já adquirida no contato com o oral seja reaplicada nessa descoberta é um fato que gera poucas dúvidas e predispõe a tomá-la como base; mas é totalmente diferente de pretender que a consciência gráfica se desenvolva a partir de elementos que estruturam a consciência fonológica. Não há nada que leve a concluir isso - nada, a não ser a sobrevivência do fonocentrismo que reina no campo da psicologia e da aflitiva preguiça intelectual quanto aos métodos de ensino de leitura.

Esse conceito por ele esboçado é aprimorado por Bajard (2014) na esteira de Richaudeau a respeito do código tipográfico, ou seja, da manipulação de caracteres para a composição das palavras no discurso:

É necessário também lembrar nossa vontade de introduzir a minúscula dentro do nome próprio desde o início do processo. No entanto, nem o espaço em branco nem a minúscula dizem respeito à pronúncia. Ao inserir esses elementos "mudos", estamos ampliando a dimensão ortográfica comum. Trata-se agora de levar em conta outro código, em uso desde a invenção da imprensa por Gutenberg: o código tipográfico com seus caracteres. (BAJARD, 2014, p. 216).

Ao manipular os caracteres já prontos, orientados por um sentido a ser criado, na leiturescrita, as crianças desenvolvem a consciência gráfica, isto é, cada caractere, letra ou não, torna-se uma unidade constitutiva de um todo e a sua posição participa da criação dos sentidos: 
Assim, podemos postular que a unidade mínima da escrita não é a letra, que possui dois formatos, nem o grafema, que depende do fonema, mas sim o caractere, cuja função provém do seu vínculo com o significado: o caractere é a menor unidade visual capaz de provocar uma mudança de significado, como ocorre em 'sol' e 'sou' (BAJARD, 2014, p 218-19).

Há, então, três conceitos articulados: um código tipográfico, que usa caracteres para compor as palavras no discurso, cuja composição desenvolve uma consciência gráfica, cuja gênese se apoia na geração de sentidos conforme sejam reordenados. Nada disso seria determinado pela subserviência à oralidade e nem sua conceituação seria dependente dela, como o grafema em relação ao fonema. Esses novos conceitos seriam resultado do próprio movimento da linguagem escrita tipográfica em passagem para a digitalizada, descolada da oral e com relativa autonomia conquistada a duras penas:

Apresentamos neste artigo argumentos a favor de uma escrita contemporânea e autônoma. Ao abordar uma língua escrita editada em "letras móveis" com caixa dupla e espaço em branco, a criança faz surgir um código ortográfico estendido, isto é, um código tipográfico constituído de caracteres dotados de uma função discursiva dentro do signo visível. Trata-se dos mesmos caracteres utilizados pelo tablet. Esse código, que vincula uma configuração visual a um significado, é o código básico da língua escrita e a criança pequena do Arrastão o manuseia muito cedo. (BAJARD, 2014, p 221-22).

Mapeado o primeiro caminho, é preciso ir para o segundo, o das crianças que não pensam linearmente, que não obedecem a único foco de atenção, que não são monoatentas, mas poliatentas. Depois de vê-las nesse mundo plural, é preciso tomar um caminho em direção ao campo da linguagem das relações textualizadas.

Em 2014, em Paris, visitei uma sala de aula de alfabetização e observei uma cena em que uma criança considerada disléxica era submetida a exercícios de desenvolvimento de consciência fonológica, mas, quando a professora tinha sua atenção atraída por outro evento, puxava do fundo de sua mesa um livro com aventuras protagonizadas por cavaleiros medievais. Para analisar essa cena, me baseei em estudos de Béslile (2011) sobre as mudanças nos comportamentos das crianças no mundo digital. Ela afirmava que os novos comportamentos não são transtornos de atenção, mas condutas de múltiplas tarefas: "mais que retomar o termo hiperatividade, é mais esclarecedor falar de poliatenção e de polifocalização." (BÉSLILE, 2010, p. 135).

Os comportamentos fora da norma, considerados transtornos de atenção, serão muito mais notados e ampliados nas escolas que se submeterem aos princípios da BNCC e do Decreto Federal, cujo núcleo paradigmático se situa no desenvolvimento da consciência fonológica e na atenção unilateral controlada em direção a uma só ação. Essas metodologias, ou métodos, desencadearão descompassos na relação entre crianças, objeto de aprendizagem e professores. As crianças poliatentas, que têm atenções direcionadas para muitos atos simultâneas, entre eles os de lidar com os aplicativos nos celulares, não suportarão o tempo morto dos exercícios e das aplicações da consciência fonológica, e, mais ainda, de um mundo gráfico que só ganha sentido se se submeter ao oral.

\section{Conclusão}

Alinhavados os temas anunciados na introdução, chego ao arremate na conclusão, apoiado nesta metáfora do trabalho minucioso e laborioso de costureiras artesanais. Recupero algumas etapas do alinhavo e as premissas defendidas em cada um. 
Tentei, inicialmente, do canto ideológico em que me situo, mapear um cenário macropolítico e, nele, analisar políticas públicas para a alfabetização, notadamente o PNAIC, implementado em governos de centro-esquerda, a BNCC, gestada nesse mesmo espectro, mas com acabamento concluído em governo de direita, e o Decreto 9.765 que determina implementação de uma política nacional de alfabetização no governo iniciado em 2019, de extrema-direita. Apesar de se situarem, do ponto de vista macropolítico, em oposição, este estudo tentou demonstrar que no âmago, isto é, na concepção de linguagem escrita e de sua natureza na configuração atual, não há divergências, porque assumem os mesmos pontos de convergência. No horizonte comum entre elas resta intocável a visão de que a escrita é mesmo integralmente alfabética.

Ao tomar como referência a linguagem escrita como pansemiótica, escapo da saia justa imposta pela visão alfabética, mais restrita, e aninho meu pensamento no campo interdisciplinar de ciências humanas que também estudam a linguagem, além da linguística. Aporto no porto das águas que banham os continentes da filosofia da linguagem, da semiótica, da antropologia, da tipografia e do digital. Acompanhado por estudiosos mais experimentados, compreendi que a linguagem escrita é organizada por caracteres, não por letras; que os caracteres são unidades que portam sentidos nos enunciados dirigidos para o outro; que, por isso, as crianças podem desenvolver uma consciência gráfica; que a relação entre linguagem digitalizada, tela e teclado rompem com a dualidade ler e escrever; que os termos alfabetização, literacia e letramento se tornam obsoletos e podem dar lugar à recuperação da palavra lecto-escrita, do mundo hispânico, disseminada pelos estudos construtivistas, que atualizo para o português brasileiro como leiturescrita e dos atos aglutinados de lescrever; essa opção se aproxima do conceito e da palavra lettrüre, recuperada do francês medieval por alguns estudiosos aqui referenciados.

Por fim, neste cenário social, cultural e antropológico, em que as relações humanas estão profundamente textualizadas em virtude do desenvolvimento da leiturescrita nos dispositivos e aplicativos na tela, com os gestos dos polegares para lescrever, as crianças, os atores que protagonizam esses atos de aprendizagem, não mais suportarão um único suporte, o papel, um único instrumento, o lápis e seus semelhantes, nem uma única atenção em direção à relação material entre fonemas e grafemas. Elas não são, nem serão mais monoatentas, mas poliatentas. Caso o paradigma de referência para a aprendizagem seja o desenvolvimento da consciência fonológica e a atenção única, borbulharão diagnósticos de doenças, acompanhados de receitas medicamentosas destinadas a domar um espírito inquieto que se debate contra o controle linear de sua mente curiosa.

\section{Referências}

BAJARD, É. O signo gráfico, chave da aprendizagem da escrita. Ensino Em Re-Vista, Uberlândia, MG, v.23, n.1, p. 201-225, jan./jun. 2016.

BÉLISLE, C. Du papier à l'écran: lire se transforme. In: BÉLISLE, C. (Org.). Lire dans um monde numérique. Villeurbanne: Presses de l'enssib, 2011.

BOUCHARDON, S. L'écriture numérique ou l'écriture selon les machines. Enjeux philosophiques et pédagogiques. Communication \& langages, n. 191, 2017.

BRASIL. Ministério da Educação. Base Nacional Comum Curricular. Disponível em: http://basenacionalcomum. mec.gov.br/a-base. Acesso em: 20 mar. 2020.

BRASIL. DECRETO NN 9.765, DE 11 DE ABRIL DE 2019 Institui a Política Nacional de Alfabetização. Disponível em: http://www.planalto.gov.br/ccivil_03/_ato2019-2022/2019/Decreto/D9765.htm. Acesso em: 20 mar. 2020. 
CAPOVILLA, F. C. (org.) Os novos caminhos da alfabetização infantil. São Paulo: Memnon, 2005.

FERREIRO, E. Reflexões sobre alfabetização. São Paulo: Cortez, 1995.

FERREIRO, E. Escrita e oralidade: unidades, níveis de análise e consciência metalinguística. In: FERREIRO, E. (Orgs.). Relações de interdependência entre oralidade e escrita. Trad. Ernani Rosa. Porto Alegre: Artmed, 2003.

FOUCAMBERT, J. A criança, o professor e a leitura. Trad. De Marleine Cohen e Carlos Mendes Rosa. Porto Alegre: Artes Médicas, 1998.

FREINET, C. O jornal escolar. Lisboa: Estampa, 1976.

KLOCK-FONTANILLE, Repenser l'écriture Pour une grammatologie intégrationnelle. Actes Sémiotiques, n¹19, 2016.

KRÄMER, S. Entre discursivité et iconicité, un nouveau regard sur les écritures Actes Sémiotiques, n¹19, 2016

RICHAUDEAU, F. Des neurones, des mots e des pixels. Reillanne: Atelier Perrousseaux Editeur, 1999.

SOUCHIER, E. Da "lettrure" à tela: ler e escrever sob o olhar das mídias informatizadas Ensino Em Re-Vista, v.22, n.1, p.211-229, jan./jun. 2015.

SOUCHIER, E. CANDEL, E.; GOMEZ-MEJIA, G. Le numérique comme écriture. Malakoff: Armand Colin, 2019.

VANDRÉ, G. Caminhando. Disponível em: <https://pt.wikipedia.org/wiki/Pra_não Dizer_que_não_Falei_das_ Flores> Acesso em: 4 abr. 2020.

Recebido em: 16/09/2020

Aceito em: 30/10/2020 